\title{
The 2016 JPED Editor Choice Awards
}

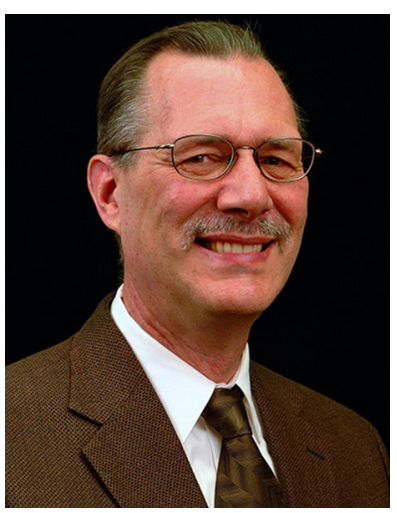

John Morral

Selection of the annual JPED Editor Choice Awards for 2016 have been made and are given below. Additional information about past awards and how selections are made can be found in the December 2015 issue of this Journal.

1. S. Cao and J.-C. Zhao, Determination of the Fe-Cr-Mo Phase Diagram at Intermediate Temperatures using Dual-Anneal Diffusion Multiples, Phase Equilib. Diff., 2016, 37(1), p 25-38.

2. X. Li, A. Scherf, M. Heilmaier, and F. Stein, The AlRich Part of the $\mathrm{Fe}-\mathrm{Al}$ Phase Diagram, Phase Equilib. Diff., 2016, 37(2), p 162-173.

3. A. Chyrkin, A. Epishin, R. Pillai, T. Link, G. Noize, and W.J. Quadakkers, Modeling Interdiffusion Processes in CMSX-10/Ni Diffusion Couple, Phase Equilib. Diff., 2016, 37(2), p 201-211.
4. K.N. Reeve, J.R. Holaday, S.M. Choquette, I.E. Anderson, and C.A. Handwerker, Advances in $\mathrm{Pb}$-free Solder Microstructure Control and Interconnect Design, Phase Equilib. Diff., 2016, 37(4), p 369-386.

5. K.-W Moon, C.E. Campbell, M.E. Williams, and W.J. Boettinger, Diffusion in FCC Co-rich Co-Al-W Alloys at 900 and $1000{ }^{\circ} \mathrm{C}$, Phase Equilib. Diff., 2016, 37(4), p 402-415.

Letters confirming the Awards have been sent via email to corresponding authors (underlined above) of each paper. Co-authors can receive a copy of the letter from their corresponding author or by sending a request to jemorral@gmail.com.

In addition to the award, papers are given "Free Access" via the Springer/JPED website http://www. springer.com/materials/journal/11669 or SpringerLink. Free access means that papers can be viewed 24/7 worldwide by anyone with an internet connection. Normally there is a charge for "Free Access," but for papers that have won this award the benefit is free.

This year it was particularly difficult to pare the "short list" of 12 papers down to the allowed number of five. We at JPED thank all authors who have sent us their fine work and heartily congratulate all who received an Editor Choice Award for 2016. On this occasion, we also wish to thank our dedicated Associate Editors and valued reviewers for their efforts to make JPED a quality publication.

John Morral

Editor in Chief

Journal of Phase Equilibria and Diffusion 